Research

Elsevier Editorial system(tm) for Fisheries

Manuscript Draft

Manuscript Number: FISH8438R1

Title: Bycatch reduction in the Norwegian Deep-water Shrimp (Pandalus borealis) fishery with a double grid selection system

Article Type: Research Paper

Keywords: Bycatch; Nordmøre grid; Pandalus borealis; Shrimp; Size selectivity

Corresponding Author: Mr. Roger B. Larsen, MSc fisheries science

Corresponding Author's Institution: University of Tromsö

First Author: Roger B. Larsen, MSc fisheries science

Order of Authors: Roger B. Larsen, MSc fisheries science; Bent Herrmann; Manu Sistiaga; Jesse Brinkhof; Eduardo Grimaldo

Manuscript Region of Origin: NORWAY

Abstract: Trawlers targeting Deep-water Shrimp (Pandalus borealis) in the North Atlantic use a Nordmore sorting grid ahead of a small-meshed codend. Based on experimental fishing, the effect of adding a $9 \mathrm{~mm}$ spaced release grid behind the mandatory $19 \mathrm{~mm}$ spaced Nordmøre sorting grid, was determined. The performance in terms of size selection of the release grid and the two grids combined were assessed for target Deep-water Shrimp and for juvenile Redfish (Sebastes spp.) and American Plaice (Hippoglossoides platessoides), two of the most common bycatch species in the fishery. The aim of using the release grid was to improve the escape of undersized shrimp and the bycatch of juvenile fish from the gear. The results demonstrated that the release grid improved the escape of the smallest Deep-water Shrimp significantly. The fraction of small shrimp released through this grid was estimated to be $45 \%$. However, the results also revealed the need for further improvements in the design of the release grid to increase the reduction of small shrimp and juvenile fish bycatch. For Redfish and American Plaice the fractions of juveniles escaping through the release grid were estimated to be $16 \%$ and $32 \%$, respectively. In addition, the release grid only led to the escape of the smallest juvenile individuals, in particular for Redfish. 


\section{Bycatch reduction in the Norwegian Deep- 2 water Shrimp (Pandalus borealis) fishery 3 with a double grid selection system}

4 Roger B. Larsen ${ }^{1 a^{*}}$, Bent Herrmann ${ }^{1,2^{*}}$, Manu Sistiaga ${ }^{2 *}$, Jesse Brinkhof ${ }^{1,2}$,

5 Eduardo Grimaldo ${ }^{2}$

$6{ }^{1}$ The Arctic University of Norway UIT, Hansine Hansens veg 18, 9019 Troms $\varnothing$, Norway

$7 \quad{ }^{2}$ SINTEF Ocean, Brattørkaia 17C, N-7010 Trondheim, Norway

$8 \quad{ }^{a}$ Corresponding author. Tel: +4777644536

$9 \quad$ E-mail address: $\underline{\text { roger.larsen@uit.no }}$

$10 \quad$ Equal authorship

\section{Abstract}

Trawlers targeting Deep-water Shrimp (Pandalus borealis) in the North Atlantic use a Nordmøre sorting grid ahead of a small-meshed codend. Based on experimental fishing, the effect of adding a $9 \mathrm{~mm}$ spaced release grid behind the mandatory $19 \mathrm{~mm}$ spaced Nordmøre sorting grid, was determined. The performance in terms of size selection of the release grid and the two grids combined were assessed for target Deep-water Shrimp and for juvenile Redfish (Sebastes spp.) and American Plaice (Hippoglossoides platessoides), two of the most common bycatch species in the fishery. The aim of using the release grid was to improve the escape of undersized shrimp and the bycatch of juvenile fish from the gear. The results demonstrated that the release grid improved the escape of the smallest Deep-water Shrimp significantly. The fraction of small shrimp released through this grid was estimated to be 45 $\%$. However, the results also revealed the need for further improvements in the design of the release grid to increase the reduction of small shrimp and juvenile fish bycatch. For Redfish and American Plaice the fractions of juveniles escaping through the release grid were 
estimated to be $16 \%$ and $32 \%$, respectively. In addition, the release grid only led to the escape of the smallest juvenile individuals, in particular for Redfish.

Keywords: Bycatch, Nordmøre grid, Pandalus borealis, Shrimp, Size selectivity

\section{Introduction}

Deep-water Shrimp (Pandalus borealis) is a commercially important species which has been fished in the North Atlantic since the 1970s. Peak landings of $105.000-128.000$ metric tons were recorded from ICES areas I and II of the Northeast Atlantic during the mid-1980s (ICES, 2017). In Norway and many other countries in the area, shrimp fisheries are often associated with a serious bycatch problem (Howell and Langan, 1992; Isaksen et al., 1992;

Grimaldo and Larsen, 2005). The bycatch issues are usually related to catching non-target fish species, however in some areas the excessive catch of small and undersized shrimp also represents a serious problem (He and Balzano, 2013; Larsen et al., 2018a). The bycatch problem in shrimp trawl fisheries is linked to the small mesh size used in the trawl (minimum diamond mesh size of $35 \mathrm{~mm}$ ), which leaves little or no chance of escape for fish or shrimp once they have entered the fishing gear (Grimaldo and Larsen, 2005). The Nordmøre grid was introduced to the Norwegian and Russian shrimp fisheries in the early 1990s, eliminating the problem of bycatch of fish larger than 25-30 cm total length (Isaksen et al., 1992; Fonseca et al., 2005; Grimaldo, 2006). Today, the Nordmøre grid is used in several shrimp fisheries around the world including Iceland, USA, Canada and Australia (Gabriel et al., 2005; Eayrs, 2007). The maximum bar spacing for the Nordmøre grid in Norway is currently $19 \mathrm{~mm}$, which does not allow bigger fish to pass through it. These fish escape by swimming out or simply sliding along the grid, before being released through the escape opening in the upper panel of the grid section. Although most fish are released through the escape opening, small- 
sized fish and juveniles of various species are still able to pass through the grid and risk being retained in the codend together with the targeted shrimp (Larsen et al., 2017).

More than 25 years after the introduction of the Nordmøre grid in the Norwegian shrimp fishery, there are still serious concerns regarding the bycatch of juvenile fish in all Norwegian shrimp fishery areas (Gullestad et al., 2015). In the Northeast Atlantic, the regulations in this fishery allow the retention of low numbers of juvenile fish from regulated species. Areas are closed if samples from $10 \mathrm{~kg}$ of shrimp catch exceed eight Cod (Gadus morhua), 20 Haddock (Melanogrammus aeglefinus), three Redfish (Sebastes spp.) or three Greenland Halibut (Reinhardtius hippoglossoides) (Norwegian Directorate of Fisheries, 2018a). Bycatch of Deep-water Shrimp below the minimum landing size (15 mm carapace length) cannot exceed $10 \%$ by weight. The bycatch rules have frequently led to the temporary closures of several large shrimp fishing grounds in the Northeast Atlantic during the last 30 years (Gullestad et al., 2015; Norwegian Directorate of Fisheries, 2018b). Because these closures can last for weeks, they can have substantial economic impacts for the fishing fleet as they may lose access to the areas with high densities of shrimp, and distances between potential fishing grounds are increased.

In recent years, efforts to reduce juvenile fish bycatch in shrimp trawls in the Northeast Atlantic have increased. This applies to the deep-sea fleet with vessels $>50 \mathrm{~m}$ length overall (e.g. Larsen et al., 2017; Larsen et al., 2018a; Larsen et al., 2018b), as well as inshore fisheries with smaller vessels. There are often small variations in the technical and gear related regulations for these vessel groups, but the selective gear is always comprised of a Nordmøre sorting grid and a size selective codend built from diamond mesh, square mesh, T90 mesh or other mesh configurations. Both deep-sea and inshore fisheries face the same challenge in terms of fish bycatch and have a common aim of finding solutions to reduce the bycatch of juvenile fish without increasing the loss of marketable shrimp. Bycatch of 
undersized shrimp and area closures are more common in the inshore and coastal shrimp trawl fisheries (Norwegian Directorate of Fisheries, 2018b), therefore solutions that could reduce the catch of the smallest sizes of shrimp in addition to reducing the bycatch of juvenile fish are sought.

Excluding juvenile fish and shrimp from the gear has many advantages. Apart from the obvious environmental advantages and increased compliance with regulations, removing any kind of unwanted catch reduces the amount of labor onboard. Sorting bycatch from the target shrimp is time consuming and can also have repercussions on the quality of the target species. To solve the aforementioned challenges, the effects of a $9 \mathrm{~mm}$ grid spaced release grid installed behind the $19 \mathrm{~mm}$ spaced Nordmøre grid was tested. The aim was to investigate the sorting performance of this release grid and to determine whether it could improve the gear selectivity in comparison with the Nordmøre grid alone. This study investigated the following research questions:

- Does the release grid installed behind the Nordmøre grid improve overall selectivity of juvenile fish and small shrimp compared to the Nordmøre grid alone?

- What is the contribution of each of the grids to the overall selectivity in the combined system using both grids?

- What fraction of small shrimp and juvenile fish bycatch that passes through the Nordmøre grid is then size selected by the release grid?

\section{Materials and Methods}

\subsection{Vessel, area, time and gear set-up}

Fishing trials were performed on board the research trawler (R/V) "Helmer Hanssen" (63.8 m length overall and 4,080 HP engine) from the $22^{\text {nd }}-24^{\text {th }}$ of February 2016 . The fishing ground chosen for the experiments was located in the North of the Barents Sea $\left(\mathrm{N} 76^{\circ} 06^{\prime}-\mathrm{E} 35^{\circ} 12^{\prime}\right.$ to $\left.76^{\circ} 04^{\prime}-\mathrm{E} 35^{\circ} 40^{\prime}\right)$ at depths of $268-278 \mathrm{~m}$. Fishing trials were carried out using a Campelen 
1800\# trawl built entirely from $80 \mathrm{~mm}$ (wings) to $40 \mathrm{~mm}$ (aft belly section) diamond meshes (Ø4 to $\varnothing 2 \mathrm{~mm}$ polyethylene twines). We used a set of Thyborön T2 otter boards $\left(6.5 \mathrm{~m}^{2}\right.$ and $2,200 \mathrm{~kg}$ ) with a $20 \mathrm{~m}$ long restrictor rope linked between the warps $80 \mathrm{~m}$ in front of the doors. The function of the restrictor rope was to keep the distance between the doors at $48-52$ $\mathrm{m}$ independent on variations in towing speed and depth. A pair of Scanmar distance (door) sensors and a Scanmar height sensor were used to monitor the door spread and height of the trawl. The height of the trawl was between $4.5 \mathrm{~m}$ and $4.8 \mathrm{~m}$ at a towing speed of $3.0-3.2$ knots $\left(1.54-1.65 \mathrm{~m}^{-\mathrm{s}}\right)$. The design used $40 \mathrm{~m}$ sweeps and a $19.2 \mathrm{~m}$ long fishing line with a rockhopper gear comprised by three sections with $\emptyset 46 \mathrm{~cm}$ rubber discs.

A four-panel standard sorting grid section, consisting of a guiding panel and a Nordmøre grid, was inserted between the trawl belly and the codend, with a fish escape opening in the upper panel just in front of the grid (Fig. 1).

\section{FIG 1}

Fishing trials were carried out with a combined selection system comprised of the Nordmøre grid followed by a release grid installed in the lower panel of the section. The codend was blinded with small meshed $(6 \mathrm{~mm})$ netting. The $19 \mathrm{~mm}$ Nordmøre grid was made of stainless steel. It was $1.5 \mathrm{~m}$ high, $0.75 \mathrm{~m}$ wide, built with $\varnothing 10 \mathrm{~mm}$ bars and an outer $\varnothing 20 \mathrm{~mm}$ steel bar frame. It was mounted so that it would maintain an angle of $45^{\circ}$ while fishing. The mean $\pm \mathrm{SD}$ bar spacing in the Nordmøre grid, measured with a caliper, was $18.8 \pm 0.4 \mathrm{~mm}$ (based on 40 measurements). The fish escape opening on the top panel just in front of the Nordmøre grid was cut as a 70 bar long and 70 mesh wide triangle, equivalent to $1.6 \mathrm{~m}$ long by $0.75 \mathrm{~m}$ wide (Fig. 1).

The $9 \mathrm{~mm}$ release grid installed behind the Nordmøre grid was $0.6 \mathrm{~m}$ wide and $1.2 \mathrm{~m}$ long. It was mounted in the section with an operating angle of ca. $20^{\circ}$ and covered $\sim 40 \%$ of the section's height (Fig. 2). A small-meshed leader panel led the escaping shrimp and fish out 
123 from the opening in the lower panel. The bar spacing in the release grid was measured to be $9.0 \pm 0.7 \mathrm{~mm}$ (based on 40 measurements). The working principle of this release grid is the opposite to that of the Nordmøre grid, as fish and shrimp that pass through the Nordmøre grid and manage to contact and pass through the release grid, escape the gear.

\section{FIG. 2}

Fish and shrimp escaping from Nordmøre grid and the release grid, were collected using two separate covers (mesh size $18.9 \pm 1.2 \mathrm{~mm}$ ) mounted over each of the grids (Fig. 2). To inflate the covers, seven Ø200 mm plastic floats on cover 1 and ca. $8 \mathrm{~kg}$ of chain weights on cover 2 were used. The fish and shrimp that passed through the Nordmøre grid and did not pass though the release grid, ended up in the blinded codend.

All hauls were conducted in the same fishing area, during the same cruise. The catch in the compartments (blinded codend and grid covers), was sorted by species for each haul. The length of each fish was measured and sorted into $1 \mathrm{~cm}$ wide length groups for fish total length and $1 \mathrm{~mm}$ wide carapace length groups for shrimp. Thus, the catch data consisted of count numbers of individuals of the different species collected in each of the compartments (cover 1 , cover 2 and blinded codend).

\subsection{Size selection model}

The size selection system employed during the cruise consisted of two contiguous sorting grids:

i) The first grid was the $(19 \mathrm{~mm})$ Nordmøre grid. If the fish and shrimp did not pass through this grid, they were released through the escape opening in the upper panel and ended up being retained in cover 1 . For a shrimp or fish to pass through the grid, two conditions need to be fulfilled: a) the fish or shrimp need to contact the grid, and b) they morphologically need to be able to pass between the bars of the 
grid, which is dependent on their size and which orientation they come in contact with the grid.

ii) If fish or shrimp pass through the first grid, provided they stay in the lower part of the trawl section, they continue towards the release grid. As is the case for the Nordmøre grid, to pass through the release grid the fish or shrimp need to contact the grid and be able to morphologically pass between the bars. The process in the release grid differs from the Nordmøre grid, with individuals that pass through the release grid escaping the gear. Those that do not pass through the release grid are retained in the blinded codend.

Therefore, for a fish or a shrimp to be retained in the blinded codend $\left(r_{\text {codend }}(l)\right)$, it would first have to pass through the Nordmøre grid, and subsequently not be released by the release grid.

Therefore, the combined size selection can be modeled by:

$r_{\text {codend }}(l)=p_{N G}(l) \times\left(1.0-p_{R G}(l)\right)$

where $l$ denotes the total length of the fish or the carapace length of the shrimp. $p_{N G}(l)$ denotes the probability of a fish or shrimp entering the zone of the Nordmøre grid and passing through it, while $p_{R G}(l)$ denotes the probability of a fish or shrimp escaping through the release grid given that it first passed through the Nordmøre grid. For both grids, the possibility that some fish or shrimp may not contact the grid at all is accounted for by fish and

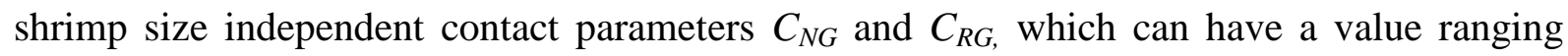
from 0.0 to 1.0 . A value close to 1.0 mean that most fish or shrimp make contact with the grid. For those fish and shrimp making contact with the grid, we assume a logit size selection model to describe the size dependent probability of pass through the grid, following (Larsen et al., 2016; Larsen et al., 2018a). Based on this, the following models were obtained for $p_{N G}(l)$ and $p_{R G}(l)$ : 


$$
\begin{gathered}
p_{N G}\left(l, C_{N G}, L 50_{N G}, S R_{N G}\right)=\frac{C_{N G}}{1.0+\exp \left(\frac{\ln (9)}{S R_{N G}} \times\left(l-L 50_{N G}\right)\right)} \\
p_{R G}\left(l, C_{R G}, L 50_{R G}, S R_{R G}\right)=\frac{C_{R G}}{1.0+\exp \left(\frac{\ln (9)}{S R_{R G}} \times\left(l-L 50_{R G}\right)\right)}
\end{gathered}
$$

172 Model (2) considers that the probability of an individual passing through the grid, given that it 173 contacts the grid, is length-dependent and decreases for larger individuals. The symbol $l$ 174 denotes the length of the individual, $L 50_{N G}$ denotes the length at which there is a $50 \%$ probability of being prevented from passing through the Nordmøre grid. The selection range $\left(S R_{N G}\right)$ describes the difference in length between individuals with a $75 \%$ and $25 \%$ probability of being prevented from passing through the Nordmøre grid. $L 50_{R G}$ and $S R_{R G}$ models for the release grid are the same as the $L 50_{R N}$ and $S R_{R N}$ models for the Nordmøre grid.

Fish or shrimp that do not pass through the Nordmøre grid are collected in the cover of the Nordmøre grid (cover 1). This probability $e_{N G}\left(l, C_{N G}, L 50_{N G}, S R_{N G}\right)$ is expressed by:

$e_{N G}\left(l, C_{N G}, L 50_{N G}, S R_{N G}\right)=1.0-p_{N G}\left(l, C_{N G}, L 50_{N G}, S R_{N G}\right)$

For a fish or shrimp to be collected in the cover of the release grid (cover 2), they first needs to pass through the Nordmøre grid and subsequently escape through the release grid. Therefore, the probability for this $e_{R G}\left(l, C_{N G}, L 50_{N G}, S R_{N G}, C_{R G}, L 50_{R G}, S R_{R G}\right)$ can be expressed by:

$e_{R G}\left(l, C_{N G}, L 50_{N G}, S R_{N G}, C_{R G}, L 50_{R G}, S R_{R G}\right)=$

As species entering the trawl differ in behavior and morphology, models (1)-(4) need to be applied separately for each different species. Therefore, the six parameters $\mathrm{C}_{\mathrm{NG}}, \mathrm{L} 50_{\mathrm{NG}}, \mathrm{SR} \mathrm{R}_{\mathrm{NG}}$, $\mathrm{C}_{\mathrm{RG}}, \mathrm{L} 50_{\mathrm{RG}}$ and $\mathrm{SR} \mathrm{RG}_{\mathrm{RG}}$ need to be estimated for each species to be able to describe the size selection in the double grid system. 
As one of the aims of this study was to determine how the Nordmøre grid combined with the release grid performed on average over the hauls conducted, the analysis included data summed over hauls $j$. The analyses were conducted separately for each species. Therefore, expression (5) was minimized, which is equivalent to maximizing the likelihood for the observed data in the form of the length-dependent number of individuals retained in the codend $\left(n C_{l}\right)$ versus those collected in the Nordmøre grid cover $\left(n N G_{l}\right)$ and in the release grid $\operatorname{cover}\left(n R G_{l}\right)$ :

$-\sum_{j=1}^{m} \sum_{l}\left\{\frac{n C_{j l}}{q C_{j}} \times \ln \left(r_{\text {codend }}\left(l, C_{N G}, L 50_{N G}, S R_{N G}, C_{R G}, L 50_{R G}, S R_{R G}\right)\right)+\frac{n N G_{j l}}{q N G_{j}} \times\right.$

$\ln \left(e_{N G}\left(l, C_{N G}, L 50_{N G}, S R_{N G}\right)\right)+\frac{n N G_{j l}}{q N G_{j}} \times$

$\left.\ln \left(e_{R G}\left(l, C_{N G}, L 50_{N G}, S R_{N G}, C_{R G}, L 50_{R G}, S R_{R G}\right)\right)\right\}$

where $q C_{j}, q N G_{j}$ and $q R G_{j}$ are the sampling factors for the fraction of individuals length measured in the codend catch and the two grid cover catches, respectively. The sampling factors comprise a value in the range 0.0 to 1.0 (1.0 if all individuals are length measured).

The outer summation in expression (5) is over the hauls conducted and the inner summation is over length classes in the data. The probabilities

$r_{\text {codend }}\left(l, C_{N G}, L 50_{N G}, S R_{N G}, C_{R G}, L 50_{R G}, S R_{R G}\right), e_{N G}\left(l, C_{N G}, L 50_{N G}, S R_{N G}\right)$ and $e_{R G}\left(l, C_{N G}, L 50_{N G}, S R_{N G}, C_{R G}, L 50_{R G}, S R_{R G}\right)$ are given by models (1)-(4).

Evaluating the ability of models (1)-(4) to describe the data sufficiently was based on calculating the corresponding $\mathrm{p}$-value. In case of poor fit statistics (p-value $<0.05$ ), the residuals were inspected to determine whether the poor result was due to structural problems when modelling the experimental data [models $(1)-(4))$ ], or due to over-dispersion in the data (Wileman et al., 1996). 
The maximum likelihood estimation using expression (5) with models (1)-(4) requires the aggregation of the experimental data from all hauls. This results in stronger data for estimating average size selectivity, but comes at the expense of not considering explicit variation in selectivity between hauls (Fryer, 1991). To account for the effect of between-haul variation in the uncertainty of the size selectivity parameters estimated, Efron percentile confidence intervals were estimated using a double bootstrap method with 1000 bootstrap iterations (Chernick, 2007; Efron, 1982). The method was applied to both the estimated parameters in expression (5) and the curves for $e_{N G}\left(l, C_{N G}, L 50_{N G}, S R_{N G}\right)$,

$e_{R G}\left(l, C_{N G}, L 50_{N G}, S R_{N G}, C_{R G}, L 50_{R G}, S R_{R G}\right)$, and $r_{\text {codend }}\left(l, C_{N G}, L 50_{N G}, S R_{N G}, C_{R G}, L 50_{R G}, S R_{R G}\right)$. The software tool SELNET (Herrmann et al., 2012) was used to carry out all selectivity data analyses.

Using the values of the selection parameters for the Nordmøre grid $\left(C_{N G}, L 50_{N G}, S R_{N G}\right)$ and the release grid $\left(C_{R G}, L 50_{R G}, S R_{R G}\right)$ in model (2), size selection curves for the two grids for stand-alone deployments were obtained. Incorporating this estimation into the bootstrapping procedure described earlier, 95\% confidence limits for the grid's stand-alone size selection curves were also produced.

\section{Results}

\subsection{Collected data}

Data from all eight hauls were used in the analyses. Trawling time was kept as constant as possible at $\sim 1 \mathrm{~h}$ (range 60-64 min). During the trials, two common and important bycatch fish species (Redfish and American Plaice) were caught in sufficient numbers to be included in the investigation. All individuals of these two species were length-measured and included in the analyses. A total of 2667 Redfish and 5430 American Plaice were measured (Table 1), and no sub-sampling was performed. Catches of Deep-water Shrimp had to be subsampled due to the 

with 4617 individuals measured.

TABLE 1.

\subsection{Size selectivity for Deep-water Shrimp}

For Deep-water Shrimp, the models used to estimate the length dependent probability for shrimp being collected in the Nordmøre grid cover, the release grid cover and the blinded codend represented the trends in the experimental data well (Fig. 3).

Therefore, despite the low p-value obtained for model fit (Table 2), models (1)-(4) could be

248 used to describe the size selection of Deep-water Shrimp both for the combined system (both 249 grids), and for the two grids individually. The low p-value was assumed to be due to overdispersion in the data, probably caused by the use of subsampled data pooled over hauls. This phenomenon has been observed in previous studies (Brčić et al., 2015, Alzorriz et al., 2016, Notti et al., 2016). The Nordmøre grid passage probability was high. This was manifested in a $253 C_{N G}$ value of $98 \%$, with a relatively high value for the lower confidence limit (Table 2). This 254 was also reflected by the fact that the probability of being collected in the Nordmøre grid cover was very low for all sizes except for the biggest shrimp (Fig. 3). The results show that the release grid significantly increased the escape of small shrimp ( $<20 \mathrm{~mm}$ carapace length)

257 compared to the Nordmøre grid alone (Fig. 4).

\section{TABLE 2}


The release efficiency of the smallest shrimp is quantified by a $C_{R G}$ value of $45 \%$. This value demonstrates that there is potential to further increase the escape efficiency of the release grid.The bar spacing $(9 \mathrm{~mm})$ used for the release grid demonstrated the ability for shrimp up to $\sim 20 \mathrm{~mm}$ carapace length to escape, which is quantified by $L 5 O_{R G}$ and $S R_{R G}$ at 18.12 and $1.96 \mathrm{~mm}$, respectively (Table 2). This implies a release probability of $25 \%, 50 \%$, and $75 \%$ for shrimp with 17,18 , and $19 \mathrm{~mm}$ carapace length, respectively, conditioned the individual contacted the release grid.

\subsection{Size selectivity for Redfish}

For Redfish, the models used to estimate the length dependent probability to be collected in the Nordmøre grid cover, the release grid cover and the blinded codend, respectively, represented the trends in the experimental data well (Fig. 3). This is further supported by a pvalue of 0.5871 , which implies that the deviation between the curves modelled and the experimental rates can well be due to coincidence (Table 2). Therefore, models (1)-(4) can be used to describe the size selection of Redfish for the combined selection system with both grids and for the two grids individually. For the Nordmøre grid, passage probability was high for the smallest Redfish. This is manifested in a high $C_{N G}$ value of $87 \%$ and the relatively high value for the lower confidence limit (Table 2). This is also reflected in the low probability of being collected in the Nordmøre grid cover for Redfish up to $\sim 10 \mathrm{~cm}$. This probability increased continuously for Redfish between 10 and $18 \mathrm{~cm}$, reaching 100\% for individuals above $20 \mathrm{~cm}$ (Fig. 3). This is driven by the size selective properties of the Nordmøre grid with $19 \mathrm{~mm}$ bar spacing quantified by the parameters $L 50_{N G}$ and $S R_{N G}$ at 13.54 $\mathrm{mm}$ and $3.61 \mathrm{~mm}$, respectively (Table 2). It seems that release grid probably only leads to a slight increase in the exclusion of very small Redfish $(<10 \mathrm{~cm})$ compared to the Nordmøre grid alone (Fig. 4). The limited escape efficiency for the smallest Redfish with the release grid is quantified by $C_{R G}$ and estimated to be only $16 \%$. However, this percentage showed wide 
confidence limits (Table 2). The size selectivity curve for the release grid (Fig. 4) demonstrates the need to improve the contact with it for Redfish, if this grid is supposed to contribute to the release of small Redfish during shrimp trawling. Further, the estimated $L 50_{R G}$ at $7.68 \mathrm{~cm}$ demonstrates that the $9 \mathrm{~mm}$ bar spacing of the release grid only supports the escape of very small Redfish (Table 2).

\subsection{Size selectivity for American Plaice}

For American Plaice, the models used to estimate the length dependent probability of being collected in the Nordmøre grid cover, the release grid cover and the blinded codend, respectively, represented the trends in the experimental data well (Fig. 3). This is further supported by a p-value of 0.9988 , which implies that the deviation between the curves modelled and the experimental rates are likely due to coincidence (Table 2). Therefore, models (1)-(4) can be used to describe the size selection of American Plaice for the combined selection system with both grids and for the two grids individually. The Nordmøre grid passage probability was very high for the smallest American Plaice. This is manifested in a $C_{N G}$ value of $100 \%$ with a very high value for the lower confidence limit (Table 2). This was also reflected by the low probability of American Plaice up to $8 \mathrm{~cm}$ in length being collected in the Nordmøre grid cover. The probability of being collected in the Nordmøre grid cover increased continuously for American Plaice between 8 and $30 \mathrm{~cm}$, with individuals over 30 $\mathrm{cm}$ having $\sim 100 \%$ probability of collection (Fig. 3). This is driven by the size selective properties of the Nordmøre grid with the given $19 \mathrm{~mm}$ bar spacing being quantified by the parameters $L 50_{N G}$ and $S R_{N G}$ at 18.22 and $8.45 \mathrm{~mm}$, respectively (Table 2). The release grid leads to an increase in escape of very small American Plaice $(<10 \mathrm{~cm})$ compared to the Nordmøre grid alone (Fig. 4). This escape efficiency for the smallest American Plaice through the release grid is quantified by $C_{R G}$ and is estimated to be $32 \%$. This value demonstrates the need to improve the contact with the release grid for American Plaice, if this grid is to 
contribute to the escape of small American Plaice while fishing. Further, the estimated $250_{R G}$ and $S R_{R G}$ at $10.14 \mathrm{~cm}$ and $4.00 \mathrm{~cm}$, respectively (Table 2), show that the release grid only supports the release of American Plaice up to about $15 \mathrm{~cm}$. At this size, the release probability for American Plaice making contact with the grid will be $<7 \%$.

\section{Discussion}

The introduction of the Nordmøre grid in shrimp fisheries has alleviated the challenge posed by bycatch (Gullestad et al., 2015; Isaksen et al., 1992; Richards and Hendrickson, 2006). However, several studies have reported that the Nordmøre grid alone does not always provide satisfactory release of fish juveniles (Clark et al., 2000; He and Balzano, 2007; Larsen et al., 2018b). Due to the design of the grid, the smallest fish and shrimp are still able to pass though the grid and be retained by the gear. For this reason, the Nordmøre grid is combined with a size selective codend. However, the combination of these two sorting devices is often not enough to provide satisfactory selectivity results and the authorities and scientific community continue to investigate potential solutions. Larsen et al. (2018a) evaluated the selectivity of a $19 \mathrm{~mm}$ Nordmøre grid and a $35 \mathrm{~mm}$ diamond mesh codend in the Barents Sea shrimp fishery. The authors concluded that "fish within a limited size range and undersized shrimp retained in the $35 \mathrm{~mm}$ codend will continue to be a problem for the northern shrimp fleet".

There have been attempts to improve selectivity in shrimp trawls by modifying the design of the Nordmøre grid (e.g. Grimaldo and Larsen, 2005; He and Balzano, 2011), by inserting an release grid in front of the Nordmøre grid (He and Balzano, 2007; He and Balzano, 2012), and by combining both approaches (He and Balzano, 2013). Some authors have also carried out sea trials where a grid with small bar spacing was installed behind the Nordmøre grid (e.g. Brothers and Boulos, 1996), but to our knowledge these data have not been scientifically reported. Therefore, no scientific information is available regarding the effect of inserting a grid with small bar spacing behind the Nordmøre grid. The new design tested in this study has 
the obvious advantage of a reduced risk of clogging the release grid by seaweed, clay, debris, etc. entering the trawl as most of it is sorted by the Nordmøre grid. Moreover, when the grids are installed in this sequence, the grid with small bar spacing is only exposed to the size distributions of shrimp and fish that are relevant for its sorting process (i.e. the smallest sizes). An additional potential challenge that is avoided by installing the release grid behind the Nordmøre grid is the release grid acting as a lifting panel reducing the contact of all fish and shrimp with the Nordmøre grid, which would be the case if installed ahead of the Nordmøre grid (He and Balzano, 2007). However, there can also be disadvantages when installing the grids in this sequence, such as reduced water flow after the Nordmøre grid (FTU, 1996). He and Balzano (2007) added a grid with $11 \mathrm{~mm}$ bar spacing in front of a $25 \mathrm{~mm}$ Nordmøre grid and reported a reduction in counts of small shrimp by $38-45 \mathrm{~kg}^{-1}$, with a mean catch rate reduction of $16 \%-39 \%$. In the present study, the selectivity performance of a release grid with $9 \mathrm{~mm}$ bar spacing behind the Nordmøre grid was investigated for two of the important and dominant bycatch species in addition to Deep-water shrimps in the Norwegian fishery. Our results proved an improvement in the overall selectivity with the new design (Fig. 4). The results showed that $45 \%$ of the shrimp that passed through the Nordmøre grid, contacted the release grid, which led to a significant increase in the escape of small shrimp $(<20 \mathrm{~mm}$ carapace length) compared to the Nordmøre grid alone.

The results of the current study confirm that adding an additional escape opportunity behind the Nordmøre grid can also be an effective way of reducing the amount of small shrimp below minimum landing size in the catch, thereby improving the overall selectivity of the gear. For American Plaice, and in particular Redfish, the fraction that passes through the Nordmøre grid and escape through the release grid was more limited and estimated to be $32 \%$ for American Plaice and $16 \%$ for Redfish. Although the contribution of the release grid was significant for 
American Plaice up to ca. $12 \mathrm{~cm}$, the results clearly show that there is a substantial potential for improvement for these two species, in particular Redfish.

Regarding the contribution of each of the grids to the overall selectivity of the gear, it is clear that both grids serve different purposes. While the Nordmøre grid is directed towards the release of fish bycatch and other unwanted marine fauna that may enter the trawl, the role of the release grid is directed towards size selectivity, specifically of the smallest shrimp and fish. The more bycatch that can escape through the release grid without losing any of the marketable shrimp, the better for the industry. The results show that the fraction of small shrimp escaping through the release grid $(45 \%)$ can be improved, but to achieve this, a higher fraction of shrimp contact with the release grid is required. There are three ways of improving grid contact; i) either by adding a guiding funnel that directs shrimp and fish passing through the Nordmøre grid towards the release grid, ii) making the angle of the release grid steeper, or iii) increasing the length of the release grid to cover a larger area. However, there are issues with these potential solutions. Adding a guiding funnel can substantially reduce water flow in an area where water the flow is already low due to the presence of the Nordmøre grid (Grimaldo and Larsen, 2005), increasing the inclination of the release grid can lead to grid clogging, i.e. shrimp and small fish get stuck between bars. In addition, a longer release grid may create handling problems due to the increased weight and dimensions.

The bar spacing of the grid is another parameter that can be changed to influence the selectivity of the release grid (He and Balzano, 2012). In principle, changing this parameter will not improve the contact of the shrimp or juvenile fish with the grid, but it can change the selectivity pattern of it and consequently the gear in one direction or another, depending on whether the bar spacing of the release grid is increased or decreased. The bar spacing of $9 \mathrm{~mm}$ used in these trials seemed to work well for the minimum landing size of $15 \mathrm{~mm}$ carapace 
length for Deep-water Shrimp in Norwegian waters. The retention probability for Deep-water Shrimp starts to increase from $\sim 15 \mathrm{~mm}$ carapace length (Fig. 4).

The overall results obtained in this study show that the escape of fish through the release grid installed behind the Nordmøre grid was not satisfactory to adhere to the current strict bycatch rules. The contact of juvenile fish was low and major improvements are necessary to reach a reduction in fish bycatch that enables the fleet to work year-round at any fishing ground.

However, while the release of juvenile fish from shrimp trawls is a major issue that receives a lot of attention, the main purpose of the release grid tested in our experiments is to optimize the size selection of the shrimp. Therefore, changes to the design of this release grid will always be constrained by the need to maintain acceptable size selectivity for shrimp.

\section{Acknowledgements}

We thank the crew of RV "Helmer Hanssen" and assistants Ivan Tatone, Lise Langård, Ingeborg Sætra, Hermann Pettersen, Tomas Araya and André Frainer for valuable assistance on board. We thank the editor and the two anonymous reviewers for valuable comments to improve our manuscript. We are grateful to the Arctic University of Norway UIT and the Norwegian Seafood Research Fund (FHF project number 901303) for funding the experiments.

\section{References}

Alzorriz, N., Arregi, L., Herrmann, B., Sistiaga, M., Casey, J and Poos, J.J., 2016.

Questioning the effectiveness of implemented technical measures under the EU landings obligation: the Basque Otter Bottom Trawl fishery case study. Fish. Res. 175, 116-126.

Brčić, J., Herrmann, B. and Sala, A., 2015. Selective characteristics of a shark-excluding grid device in a Mediterranean trawl. Fish. Res. 172, 352-360.

Brothers, G. and Boulos, D., 1996. Size sorting shrimp with an in-trawl grid system. Report of the ICES-FAO Working Group on Fishing Technology and Fish Behaviour (WGFTFB). ICES CM 1996/B: 2. 45 pp. 
Chernick, M.R., 2007. Bootstrap Methods: A guide for practitioners and researchers, second edition. Wiley series in probability and statistics. Wiley, New York.

Clark, S. H., Cadrin, S. X., Schick, D. F., Doidati, P. J., Armstrong, M. P. and McCarron, D., 2000. The Gulf of Maine northern shrimp (Pandalus borealis) fishery: a review of record. J. Northw. Atl. Fish. Sci. 27, 193-226.

Eayrs, S., 2007. A Guide to Bycatch Reduction in Tropical Shrimp-Trawl Fisheries [Revised edition]. FAO, Rome. 108 pp.

Efron, B., 1982. The jackknife, the bootstrap and other resampling plans, SIAM Monograph No. 38, CBSM-NSF.

Fonseca, P., Campos, A. and Larsen, R., 2005. Using a modified Nordmøre grid for bycatch reduction in the Portuguese crustacean-trawl fishery. Fish. Res. 71, 223-239.

Fryer, R.J., 1991. A model of between-haul variation in selectivity. ICES J. Mar. Sci. J. Cons. 48, 281-290.

FTU, 1996. Tests of an experimental size-selective shrimp grate in a Skjervøy shrimp trawl. Fishing Technology Unit Report No. 5/96. Fisheries and Marine Institute, St John's, Newfoundland, 31 pp.

Gabriel, O., Lange, K., Dahm, E. and Wendt, T., 2005 (eds.). Fish catching methods of the world. $4^{\text {th }}$ ed. Oxford. Blackwell Publishing Ltd. 523 pp.

Grimaldo, E., 2006. The effects of grid angle on a modified Nordmøre-grid in the Nordic Shrimp Fishery. Fish. Res. 77, 53-59.

Grimaldo, E. and Larsen, R. B., 2005. The cosmos grid: a new design for reducing bycatch in the Nordic shrimp fishery. Fish. Res. 76, 187-197.

Gullestad, P., Blom, G.., Bakke, G. and Bogstad, B., 2015. The "Discard Ban Package": Experiences in efforts to improve the exploitation patterns in Norwegian fisheries, Marine Policy, 54, 1-9, dx.doi.org/10.1016/j.marpol.2014.09.025.

He, P. and Balzano, V., 2013. A new shrimp trawl combination grid system that reduces small shrimp and finfish bycatch. Fish. Res. 140, 20-27.

He, P. and Balzano, V., 2012. The effect of grid spacing on size selectivity of shrimps in a pink shrimp trawl with a dual-grid size-sorting system. Fish. Res. 121-122, 81-87. 
He, P. and Balzano, V., 2011. Rope Grid: a new grid design to further reduce finfish bycatch in the Gulf of Maine pink shrimp fishery. Fish. Res. 111, 100-107.

He, P. and Balzano, V., 2007. Reducing small shrimps in the Gulf of Maine pink shrimp fishery with a new size-sorting grid system. ICES J. Mar. Sci. 64, 1551-1557.

Herrmann, B., Sistiaga, M. B., Nielsen, K. N. and Larsen, R. B., 2012. Understanding the size selectivity of redfish (Sebastes spp.) in North Atlantic trawl codends. J. Northw. Atl. Fish. Sci. 44, 1-13.

Howell, W. H. and Langan, R., 1992. Discarding of commercial groundfish species in the Gulf of Maine shrimp fishery. N. Am. J. Fish. Man. 12, 568-580.

ICES, 2017. ICES Advice on fishing opportunities, catch, and effort Arctic Ocean, Barents Sea, Faroes, Greenland Sea, Iceland Sea, and Norwegian Sea ecoregions - Northern shrimp (Pandalus borealis) in subareas 1 and 2 (Northeast Arctic). Published 27 October 2017 pra.27.1-2 DOI: 10.17895/ices.pub.3356.

Isaksen, B., Valdemarsen, J.W., Larsen, R.B. and Karlsen, L., 1992. Reduction of fish bycatch in shrimp trawl using a rigid separator grid in the aft belly. Fish. Res. 13, 335-352. Larsen, R.B., Herrmann, B., Sistiaga, M.B., Brinkhof, J., Tatone, I. and Langård, L., 2018a. New approach for modelling size selectivity in shrimp trawl fisheries. ICES J. Mar. Sci.; 75 (1), 351-360. doi: 10.1093/icesjms/fsx117.

Larsen, R.B., Herrmann, B., Sistiaga, M.B., Brcic, J., Brinkhof, J. and Tatone, I., 2018b. Could green artificial light reduce bycatch during Barents Sea Deep-water shrimp trawling? Fish. Res., 204, 441-447, doi: https://doi.org/10.1016/j.fishres.2018.03.023.

Larsen, R. B., Herrmann, B., Sistiaga, M., Brinkhof, J., Tatone, I. and Langård, L., 2017. Performance of the Nordmøre grid in shrimp trawling and potential effects of guiding funnel length and light stimulation. Marine and Coastal Fisheries, 9, 479-492.

Larsen, R.B., Herrmann, B., Sistiaga, M., Grimaldo, E., Tatone, I. and Onandia, I., 2016. Size selection of redfish (Sebastes spp.) in a double grid system: Quantifying escapement through individual grids and comparison to former grid trials. Fish. Res. 183, 385-395.

Norwegian Directorate of Fisheries, 2018a. J-23-2018: Regulation on mesh size, bycatch and minimum landing sizes, etc. during fishery in the Svalbard Zone (in Norwegian). https://www.fiskeridir.no/Yrkesfiske/Regelverk-og-reguleringer/J-meldinger/Gjeldende-Jmeldinger/J-23-2018 
469 Norwegian Directorate of Fisheries, 2018b. Area closures for shrimp trawling north of $62^{\circ} \mathrm{N}$

470 (in Norwegian). https://www.fiskeridir.no/Yrkesfiske/Regelverk-og-reguleringer/Stenging-og-

471 aapning/Nord-for-62-N/Reketraal

472 Notti, E., Brčić, J., De Carlo, F., Herrmann, B., Lucchetti, A., Virgili, M. and Sala, A., 2016.

473 Assessment of the relative catch performance of a surrounding net without the purse line as an

474 alternative to a traditional boat seine in small scale fisheries. Marine and Coastal Fisheries, 8,

$475 \quad 81-91$.

476 Richards, A. and Hendrickson, L., 2006. Effectiveness of the Nordmøre grate in the Gulf of

477 Maine northern shrimp fishery. Fish. Res. 81, 100-106.

478 Wileman, D. A., Ferro, R. S. T., Fonteyne, R., and Millar, R. B. (Eds.), 1996. Manual of 479 methods of measuring the selectivity of towed fishing gears. ICES Cooperative Research 480 Report No. 215. 


\section{Tables:}

Table 1: Overview of the fish and shrimp length measured in the hauls carried out during the trials. $n C$ : number in the codend. $n N G$ : number in the Nordmøre grid cover. $n R G$ : number in the release grid cover. For Deep-water Shrimp values in parentheses represent the fraction $(\%)$ of the total number of individuals caught being length measured ( $q N G, q R G$ and $q C$ times 100). For Redfish and American Plaice all individuals caught were length measured.

\begin{tabular}{lccccccccc}
\hline Haul & \multicolumn{3}{c}{ Deep-water Shrimp } & & \multicolumn{3}{c}{ Redfish } & & \multicolumn{3}{c}{ American Plaice } \\
ID & $n N G$ & $n R G$ & $n C$ & $n N G$ & $n R G$ & $n C$ & $n N G$ & $n R G$ & $n C$ \\
\hline 1 & $123(9.34)$ & $259(37.20)$ & $153(1.64)$ & 242 & 1 & 67 & 424 & 14 & 182 \\
2 & $133(100.00)$ & $320(36.33)$ & $162(1.54)$ & 174 & 1 & 91 & 417 & 19 & 301 \\
3 & $100(39.16)$ & $321(16.64)$ & $194(1.00)$ & 149 & 16 & 164 & 378 & 33 & 363 \\
4 & $0(100.00)$ & $313(12.99)$ & $135(0.88)$ & 381 & 3 & 169 & 402 & 41 & 372 \\
5 & $144(30.58)$ & $363(16.53)$ & $158(0.91)$ & 216 & 3 & 63 & 302 & 14 & 190 \\
6 & $112(40.00)$ & $247(12.56)$ & $147(0.94)$ & 204 & 2 & 53 & 347 & 21 & 273 \\
7 & $175(22.76)$ & $307(7.67)$ & $155(0.77)$ & 189 & 13 & 130 & 304 & 20 & 275 \\
8 & $138(8.70)$ & $332(18.11)$ & $126(1.36)$ & 309 & 0 & 27 & 426 & 22 & 290 \\
\hline
\end{tabular}

Table 2: Parameter values and fit statistics for models (1)-(4) applied in the estimation by minimizing expression (5). Values in parentheses are $95 \%$ confidence intervals. *: mm for Deep-water Shrimp. DOF denotes degrees of freedom.

\begin{tabular}{lccc}
\hline \multicolumn{1}{c}{ Parameter } & Deep-water Shrimp & Redfish & American Plaice \\
\hline$C_{N G}$ & $0.98(0.96-1.00)$ & $0.87(0.75-0.94)$ & $1.00(0.98-1.00)$ \\
$L 50_{N G}\left(\mathrm{~cm}^{*}\right)$ & $33.79(29.16-44.55)$ & $13.54(12.85-14.22)$ & $18.22(17.16-19.15)$ \\
$S R_{N G}\left(\mathrm{~cm}^{*}\right)$ & $6.83(3.53-12.98)$ & $3.61(2.94-4.35)$ & $8.45(7.49-9.39)$ \\
$C_{R G}$ & $0.45(0.33-0.64)$ & $0.16(0.03-1.00)$ & $0.32(0.23-0.60)$ \\
$L 50_{R G}\left(\mathrm{~cm}^{*}\right)$ & $18.12(17.29-18.62)$ & $7.68(0.10-12.02)$ & $10.14(6.40-11.84)$ \\
$S R_{R G}\left(\mathrm{~cm}^{*}\right)$ & $1.96(1.70-2.45)$ & $3.56(0.10-10.85)$ & $4.00(2.53-6.24)$ \\
p-value & 0.0164 & 0.5871 & 0.9988 \\
Deviance & 58.90 & 47.18 & 49.98 \\
DOF & 38 & 50 & 84 \\
\hline
\end{tabular}




\section{Figure legends:}

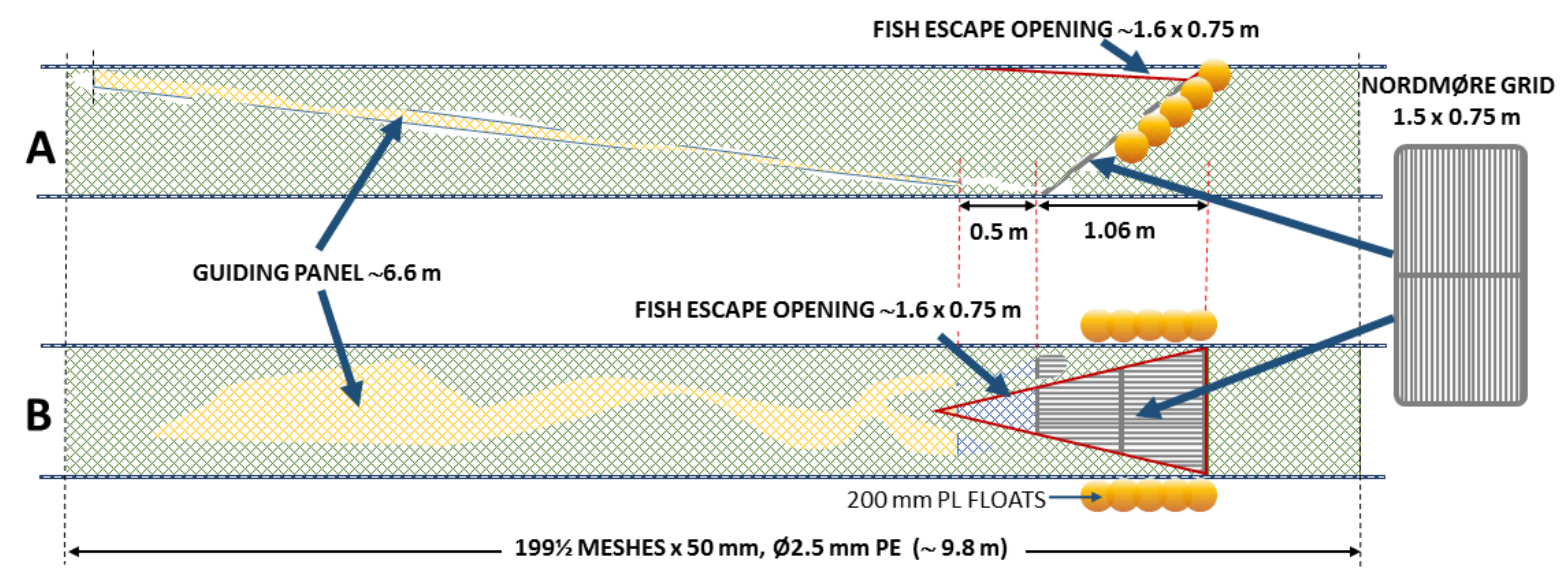

Fig. 1: The four-panel Nordmøre grid section seen from the side (A) and from above (B), with some of the construction details illustrated.

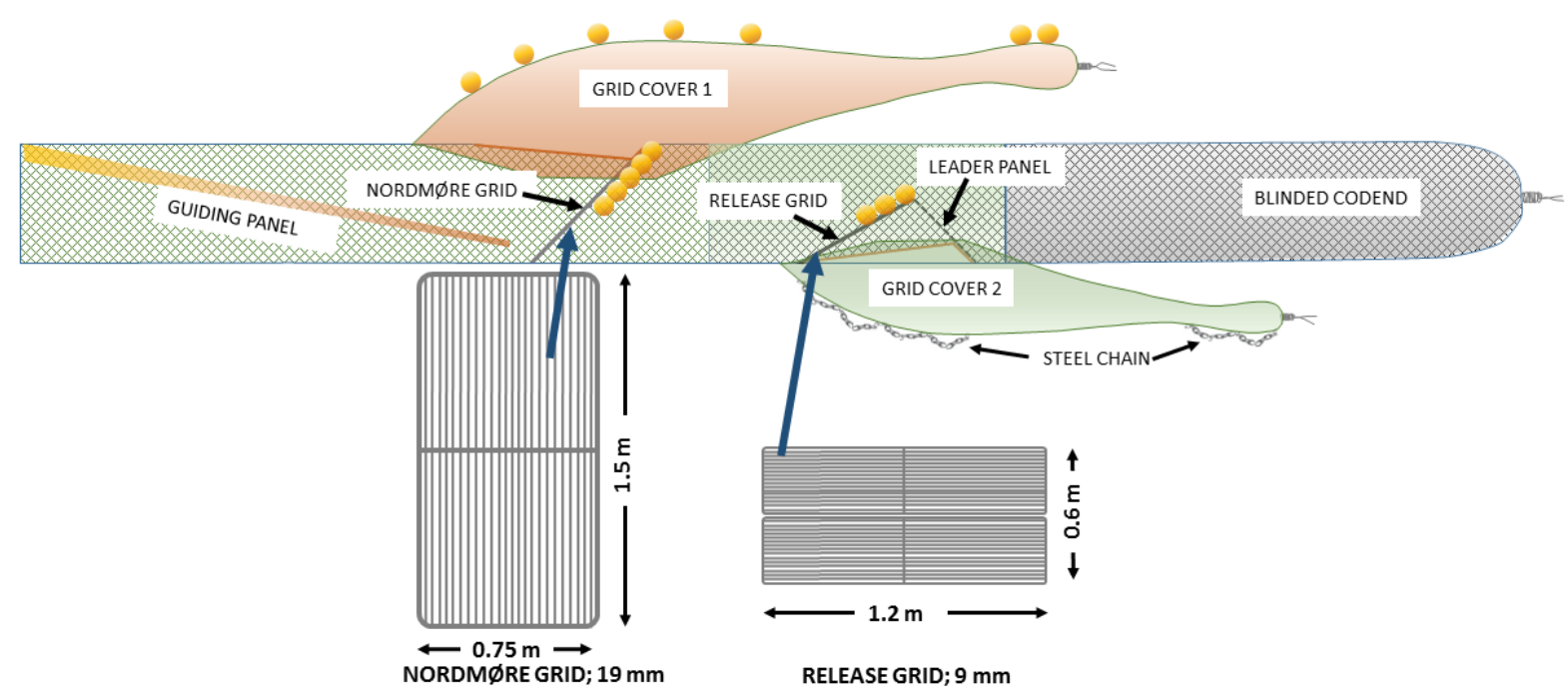

Fig. 2: Illustration of the experimental design with the Nordmøre grid and the release grid.

The small circles represent $\varnothing 200 \mathrm{~mm}$ plastic floats. 

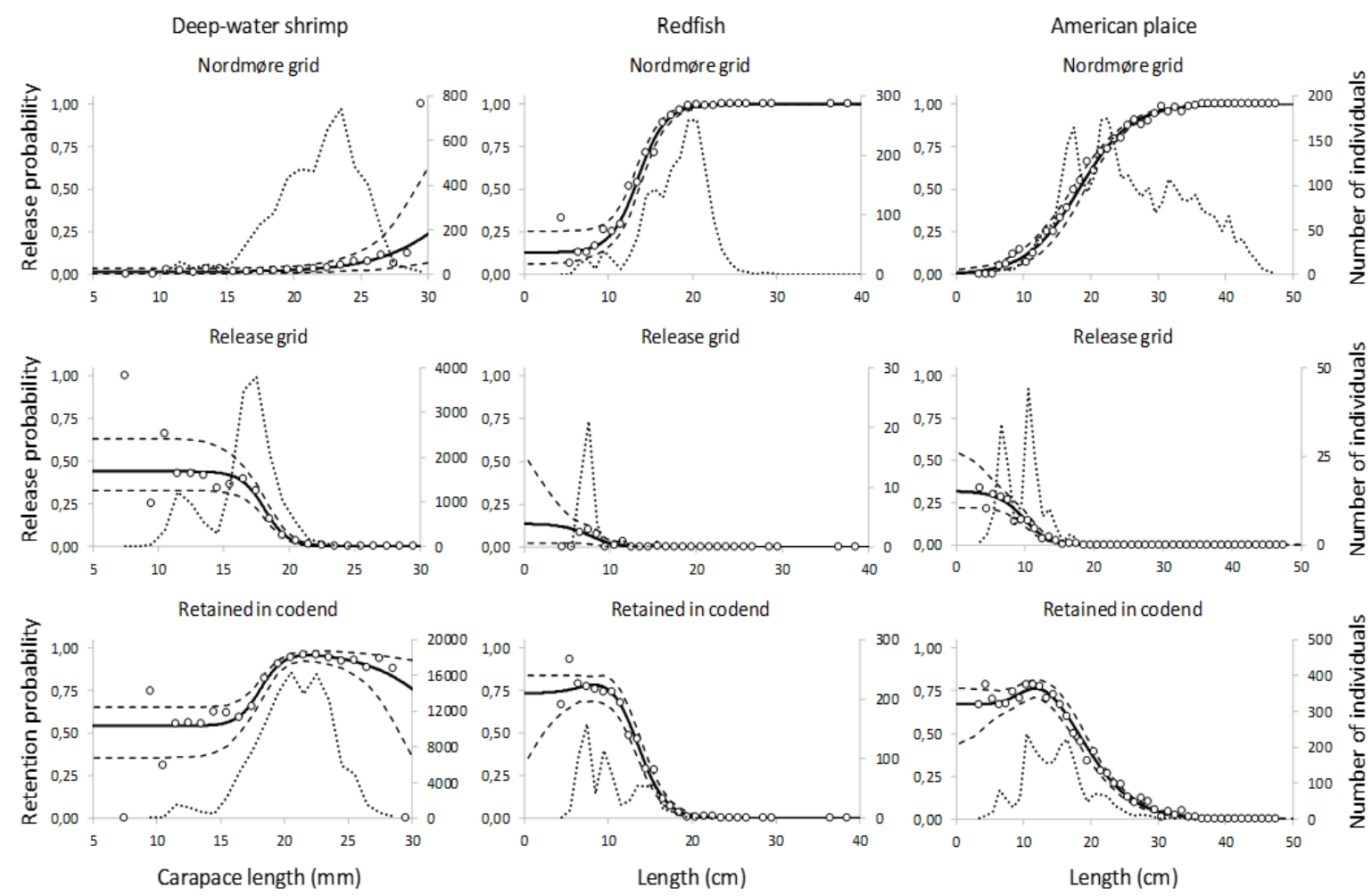

Fig. 3: Length dependent probabilities of Deep-water Shrimp (left column), Redfish (center column) and American Plaice (right column) collected in the Nordmøre grid cover (top row), the release grid cover (center row) and the blinded codend (bottom row), respectively. Circles represent the experimental rates, and the solid black curve represents the modelled rate. The dashed curves represent $95 \%$ confidence limits for the modelled rate, while dotted curves represent the size distributions collected in the three compartments (Fig. 2). 

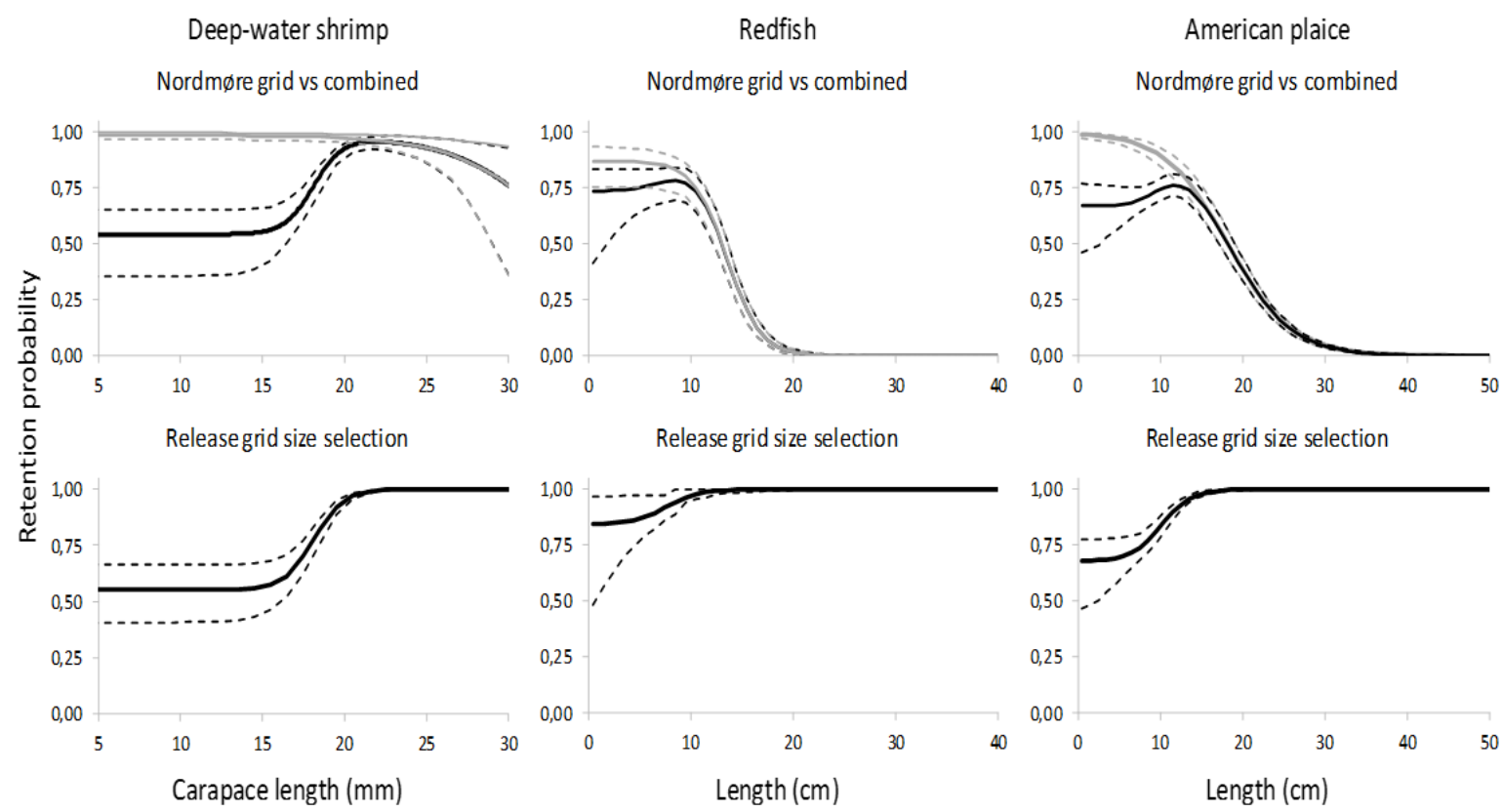

Fig. 4: Comparison (top row) of the double grid retention probability (black) for Deep-water Shrimp, Redfish and American Plaice with the retention probability for the Nordmøre grid alone (grey) and size selection (retention probability) for the release grid alone (bottom row). Dashed curves represent 95\% confidence limits. 